\title{
Pressure Monitoring in Tunnel Grouting Simulation Test
}

\author{
Li Peng ${ }^{1}$, He Lingyao', Wang Kai², Wang Qian'*, Zhang Qingsong ${ }^{3}$, Zhang Xiao ${ }^{3}$ \\ ${ }^{1}$ Engineering College, Ocean University of China, Qingdao, 266100, China \\ ${ }^{2}$ Shandong Hi-Speed Group, Jinan, 250061, China \\ ${ }^{3}$ Geotechnical and Structural Engineering Research Center, Shandong University, Jinan, 250061, China
}

Received: 28 July 2021

Accepted: 15 October 2021

\begin{abstract}
The grouting methods have been widely adopted to improve the mechanical properties of weak rock masses in civil engineering, while the current study on grouting mechanism is still limited. Pressure monitoring is one of the most challenging problems when doing experimental tests on mockups and scaled models to study grouting mechanism. Based on a tunnel engineering case, this paper developed a grouting test to verify feasibility of the use of Fiber Bragg Grating (FBG) sensors in monitoring the pressure generated by grout injection, as well as to obtain the relationship between it and the external pipeline pressure. A total of 14 FBG sensors, mainly in the vault, spandrel and hance of the tunnel arch, were installed into the scaled model. Then, three grout injections were implemented to strengthen the weak rock mass. It could be measured that the average pressure increment and peak pressure increment of each sensor in the M1 grouting could reach $13 \mathrm{kPa} 79 \mathrm{kPa}$ and $25 \mathrm{kPa} \sim 89 \mathrm{kPa}$, respectively. The FBG sensors are therefore capable of monitoring the pressure caused by grouting. In addition, there was a pressure loss when the grout flowed from the pipes to the rock mass, which can reach $53.8 \% \sim 82.9 \%$, i.e. the pipeline pressure was larger than the actual pressure that drives grout diffusion, and this is mainly caused by the pipe friction and grout viscosity resistance. Therefore, a certain reduction coefficient should be taken when using external pipeline pressure to calculate the grout diffusion radius in engineering applications, otherwise the calculated values will be too large.
\end{abstract}

Keywords: scaled models, grout injection, pressure monitoring, pressure loss

\section{Introduction}

For practical purposes, the grouting methods, with the advantages of pretty good safety and economy, have been widely used to improve the mechanical properties of weak rock mass in the fields of tunnels, mines, metros,

*e-mail: wq1219@ouc.edu.cn highways and dams [1-4]. Driven by high pressure provided by pumping equipment, the grouts are injected into ground through the grouting pipes to densify and combine with it, thus improving its properties. To perform an efficient grouting intervention, an accurate planning of the grouting method is necessary, however, the current understanding of grouting mechanism is still limited, which conditions the design of grouting engineering to empirical methods [5-7]. 
The grouting test method can closely simulate the actual working conditions of grouting engineering, then it has been increasingly used to study grouting mechanism in the past few decades. For example, Zhang [8], Du [9], Bolisetti [10] and Gothäll [11] conducted grouting tests to study grouting diffusion mechanism in porous media, respectively. Yun et al. [12] experimentally investigated the injection process of fracture grouting in weathered granite soil. Murdoch [13-15] developed an experiment setup to study the shape and dimensions of grout fractures in clay soil. Nevertheless, these tests are limited to the final shape of solidified grout body that was exposed in the excavation for rock mass after grouting. On this basis, Li et al. [16] and Sui et al. [17] conducted experimental investigation on grout diffusion mechanism in transparent fracture replica to obtain the real-time and dynamic diffusion process of grout, and the parameter of injection velocity was also measured by use of fiber optical sensors, while the key parameters such as pressure generated by grouting could not be obtained, which resulted in insufficient analysis of grouting mechanism. This is mainly because pressure generated by grouting is the basic data needed to calculate key parameters such as grout diffusion radius in engineering applications, therefore, the pressure monitoring has become one of the important problems restricting the further development of grouting tests. For traditional monitoring methods, the pressure monitoring is usually achieved by pressure gauges, but only limited to the external pipeline pressure, which is directly adopted in relevant calculations such as grout diffusion radius. However, the external pipeline pressure is not equal to the pressure driving the grout diffusion, and this will lead to some calculation errors. Therefore, it is necessary to obtain the relationship between the external pipeline pressure and the pressure that actually drives grout diffusion.

To offer a contribution to the solution of the aforementioned problem, an experiment was made on a scaled model to verify the feasibility of Fiber Bragg Grating (FBG) sensors in monitoring the pressure generated by grout injection. A total of 14 FBG sensors were installed into the scaled model to measure the real-time pressure during grouting, which is the actual pressure that drives grout diffusion, also to obtain the relationship between it and the external pipeline pressure.

\section{Material and Methods}

\section{Scaled Grouting Test System}

Yonglian tunnel, located at the highway from Ji'an City to Lian'hua City, in Jiangxi Province, China, built between 2012 and 2015, suffered multiple rock mass failure such as collapse and mud inrush during the construction process [18-21]. This was mainly due to the exposure of the fault during the tunnel excavation, and it is composed of highly weathered sandstone and shale with extremely low strength and permeability. Hence, the grouting method was applied to improve the properties of weak rock mass. On this basis, a set of test system is developed to study grouting mechanism, also to provide parameters references for engineering applications.

The test design follows the similarity principle, with a similar ratio of 1:60 to Yonglian tunnel. The tunnel diameter is therefore selected as $150 \mathrm{~mm}$. The test system consists of scaled model (see Fig. 1), grouting pumping equipment, and multi-parameter acquisition module. The grouting equipment is a manual grouting pump, the injection pressure of which can reach $5 \mathrm{MPa}$, and the flow rate per stroke is $0.1 \mathrm{~L}$. By adjusting the pumping frequency, the injection rate can be controlled to achieve the grouting under the conditions of small flow and high pressure. Considering that tunnel excavation is actually affected by geostress, on basis of the same similarity ratio, the geostress of $0.3 \mathrm{MPa}$ is applied to the test device by using hydraulic oil cylinder. In addition, a steel plate is placed on top of the test device. On this basis, the hydraulic pressure is loaded to the center of the steel plate, through which the pressure could be transmitted to achieve uniform geostress loading. The geostress loading needs to be conducted before grouting procedure. Pressure monitoring is an important component of the multi-parameter acquisition module, and the pressure sensors are installed inside the scaled model.

\section{Selection of Pressure Sensors}

By using pressure gauge, the traditional monitoring methods only focus on pipeline pressure, but cannot monitor the pressure inside the rock mass. In this

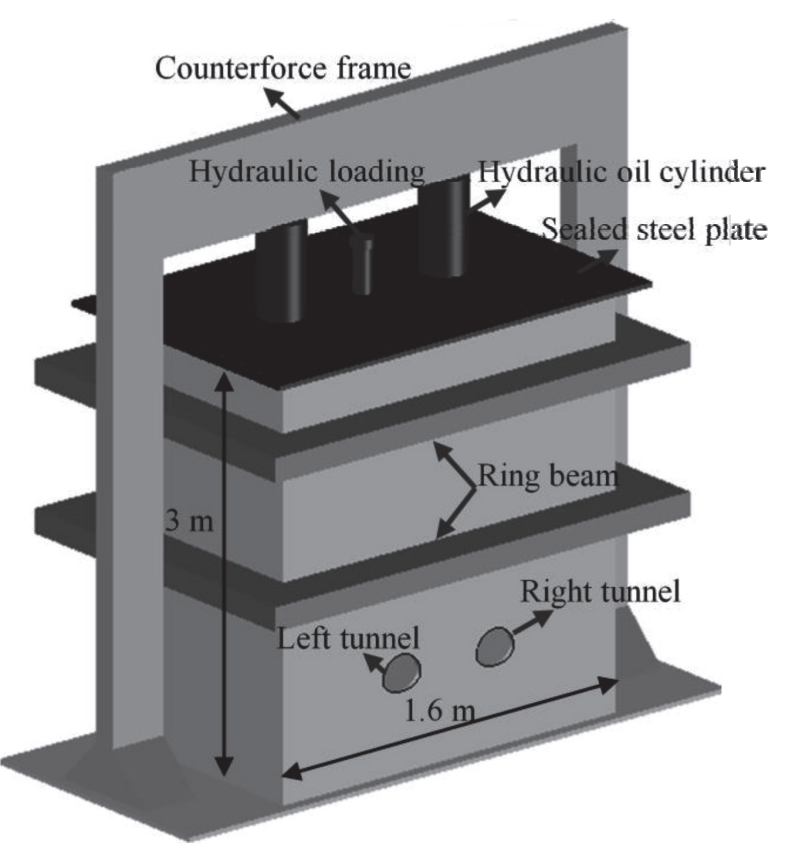

Fig. 1. Sketch of the scaled model. 


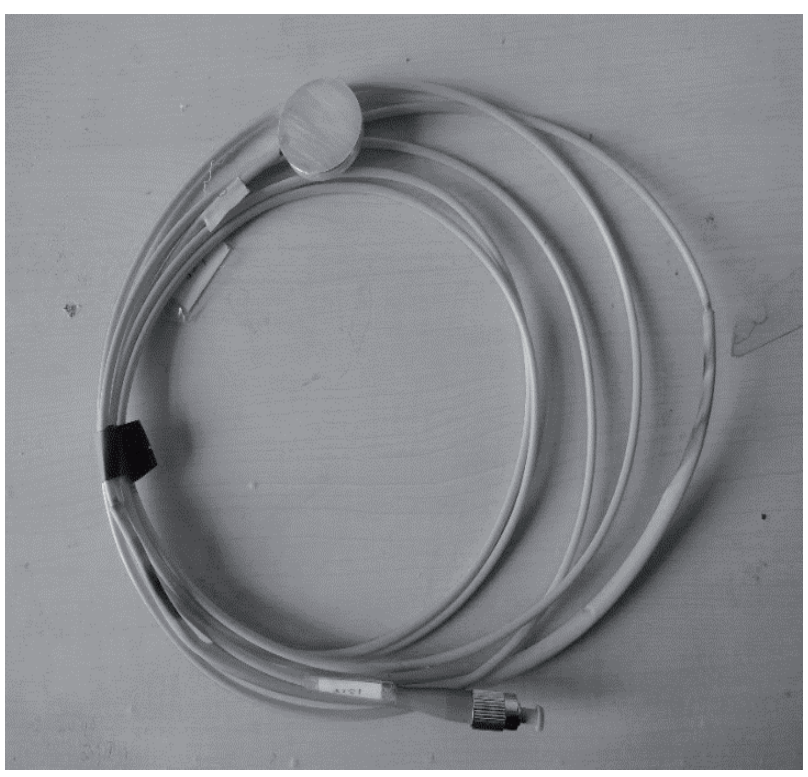

Fig. 2. Picture of FBG sensors.

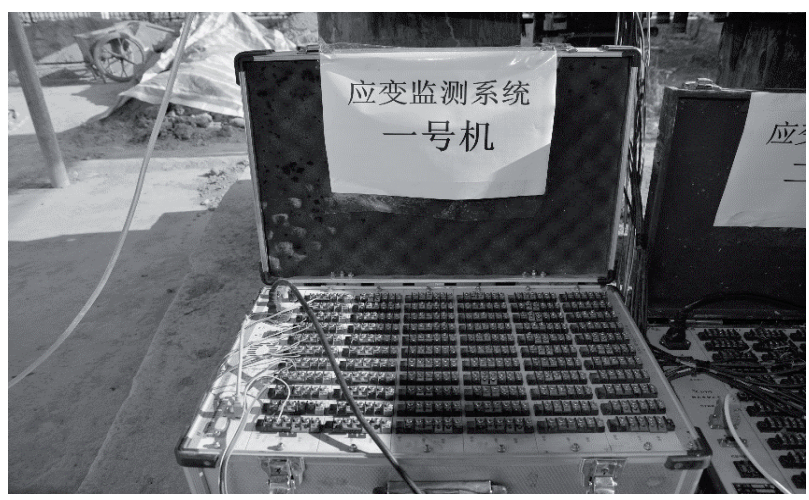

Fig. 3. Picture of static strain instrument.

study, pressure monitoring of rock mass is realized by means of built-in sensors. The size of the sensor should be as small as possible in the grouting test to avoid interference with the grout diffusion path. Furthermore, the grouting test is usually performed under the condition of high injection pressure [22-25], therefore, the pressure measurement range of the sensor should be large enough. Given this, the FBG sensors (Fig. 2), with the advantages of small size, high precision, large range and small error as tabulated in Table 1, were selected to monitor the pressure generated by grouting in the test.

The pressure sensors are coupled by a multichannel grating demodulator (developed by Shandong University), which can realize the parallel acquisition of
Table 2. Locations and label of FBG sensors.

\begin{tabular}{|c|c|c|c|}
\hline Section & Location & $\begin{array}{c}\text { Distance } \\
(\mathrm{mm})\end{array}$ & Label \\
\hline LV1 & Vault & 50 & LV1SP \\
\hline LV2 & Vault & 150 & LV2SP \\
\hline LV3 & Vault & 250 & LV3SP \\
\hline RV1 & Vault & 50 & RV1SP \\
\hline RV2 & Vault & 150 & RV2SP \\
\hline RV3 & Vault & 250 & RV3SP \\
\hline LS1 & Spandrel & 50 & LS1SP \\
\hline LS2 & Spandrel & 150 & LS2SP \\
\hline RS1 & Spandrel & 50 & RS1SP \\
\hline RS2 & Spandrel & 150 & RS2SP \\
\hline S3 & Spandrel & 250 & S3SP \\
\hline LM1 & Hance & 100 & LM1SP \\
\hline RM1 & Hance & 100 & RM1SP \\
\hline M2 & Hance & 300 & M2SP \\
\hline
\end{tabular}

multiple sensors. Besides, the static strain instrument, as shown in Fig. 3, with stable performance, good antiinterference ability and fast scanning capability, is used for the output of the pressure data. In this way, the pressure generated by grouting in the rock mass could be presented in real time.

\section{Layout and Installation of FBG Sensors}

The FBG sensors were mainly placed in the locations where failure were expected such as vault, spandrel and hance of the tunnel arch. In addition, other sensors were placed around the tunnel excavation contour line. The influence of grouting pressure on surrounding rock is different near and far from the excavation contour line, in order to obtain relevant pressure data, there was a total of 3 sections with the distance from the contour line $50 \mathrm{~mm}, 150 \mathrm{~mm}, 250 \mathrm{~mm}$, respectively. The left and right tunnels were provided with sensors in the same way. A total of 14 FBG sensors were installed inside the scaled model, as shown in Table 2 and Fig. 4.

According to the designed locations, the FBG sensors were installed into the scaled model. The specific procedure for installation was positioning, trenching, placing sensors and filling, as shown in Fig. 5.

Table 1. The main parameters of FBG sensors.

\begin{tabular}{|c|c|c|c|c|}
\hline Range & Precision & Measurement error & Connector & Size \\
\hline $0 \sim 2 \mathrm{MPa}$ & $\pm 20 \mathrm{~Pa}$ & $<3 \mathrm{kPa}$ & Standard FC & $\varphi 25 \times 10 \mathrm{~mm}$ \\
\hline
\end{tabular}




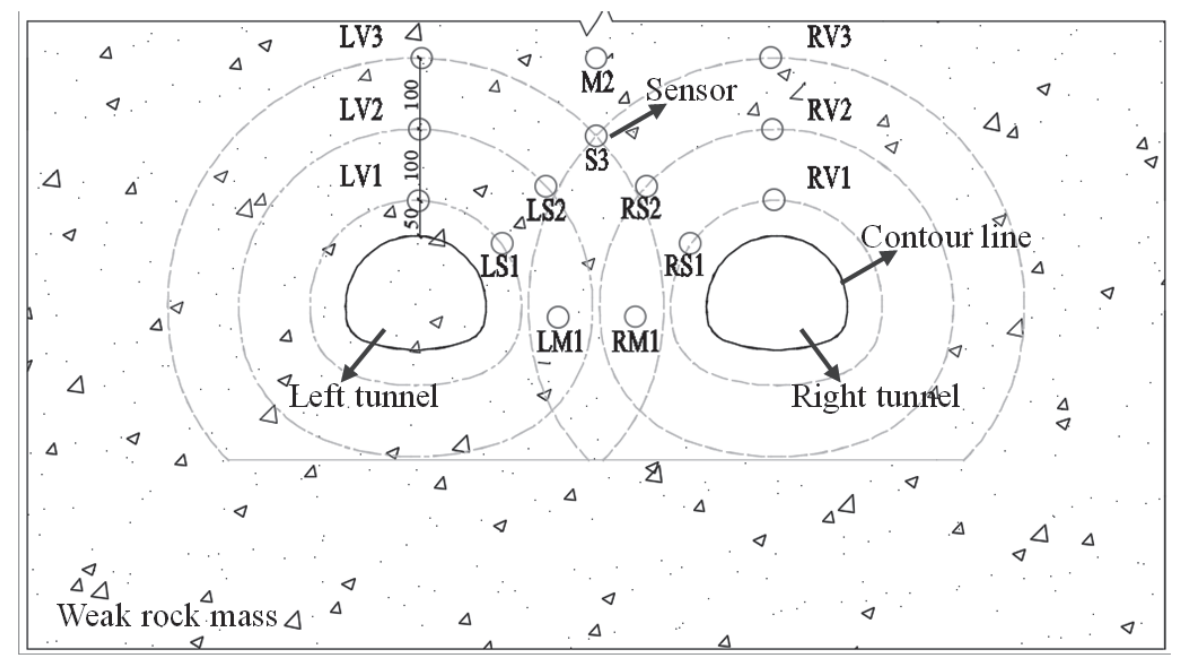

Fig. 4. Diagram of FBG sensors layout.

\section{Design and Implementation of Grouting Method}

The grout injection process was performed after water and mud inrush of the tunnel in the test, therefore, the weak rock mass above the tunnel was the key place that needs to be strengthened. As illustrated in Fig. 6a), three sets of grouting pipes (L1, R1 and M1) with a same inner diameter of $8 \mathrm{~mm}$ and a same length of $745 \mathrm{~mm}$ were installed into the scaled model, and the distances from their tops to the tunnel excavation contour line were $78 \mathrm{~mm}, 46 \mathrm{~mm}$ and $78 \mathrm{~mm}$, respectively. Grout injection could be realized by the grouting pumping equipment, which is a power device for injecting grout into the rock mass. On this basis, three grout injections were implemented to strengthen the weak rock mass above the left tunnel, right tunnel and their middle area, respectively, so as to realize the comprehensive improvement of the properties of the weak rock mass. a)

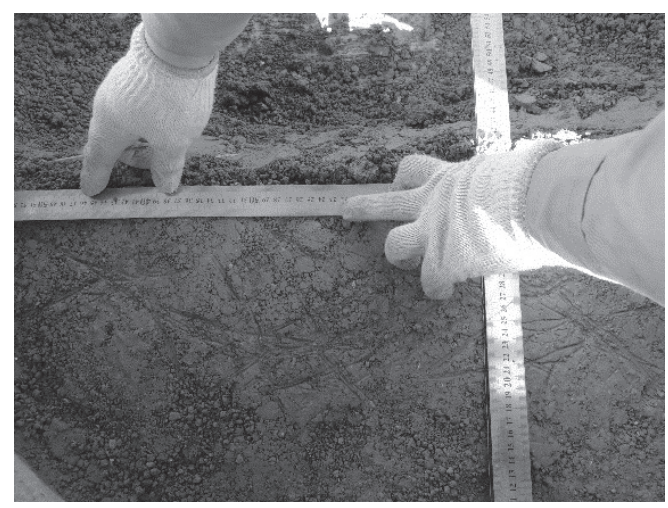

c)

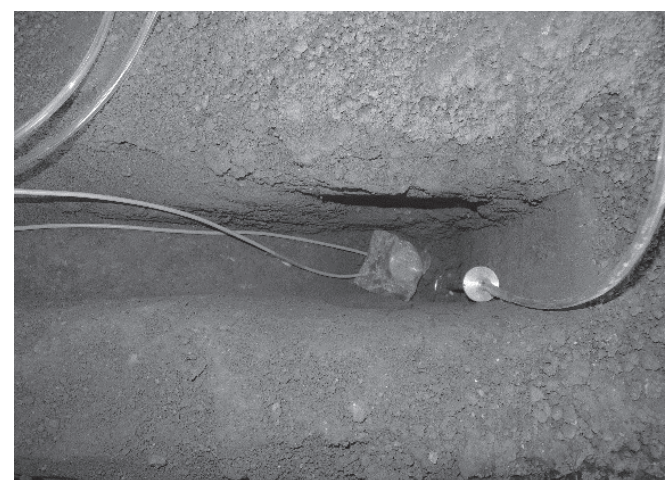

b)

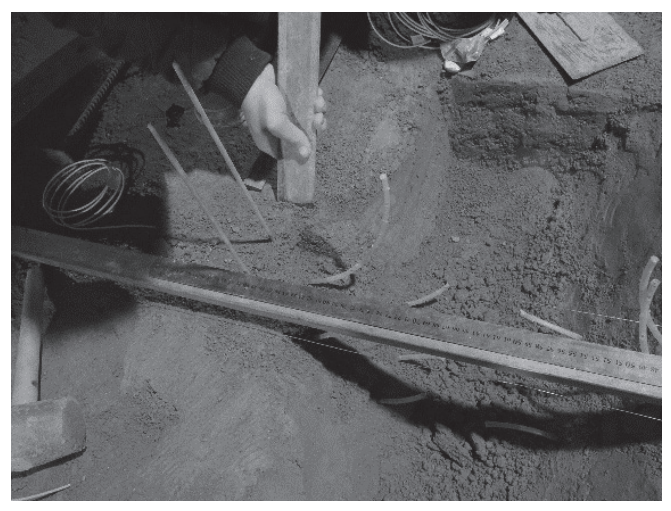

d)

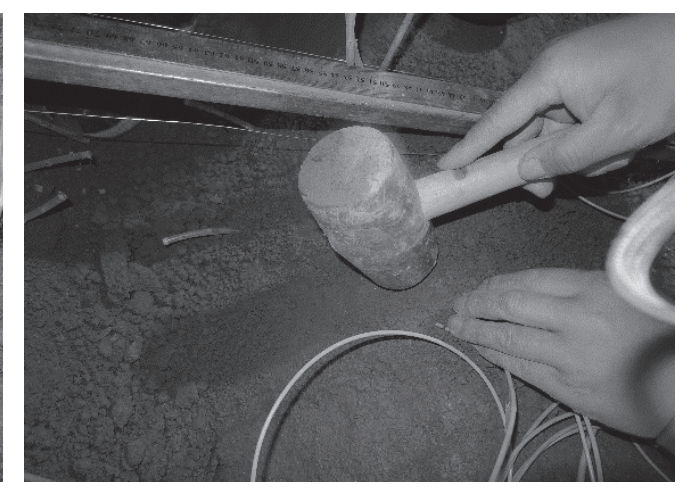

Fig. 5. Diagram of sensors installation: a) positioning, b) trenching, c) placing sensors, d) filling. 
a)

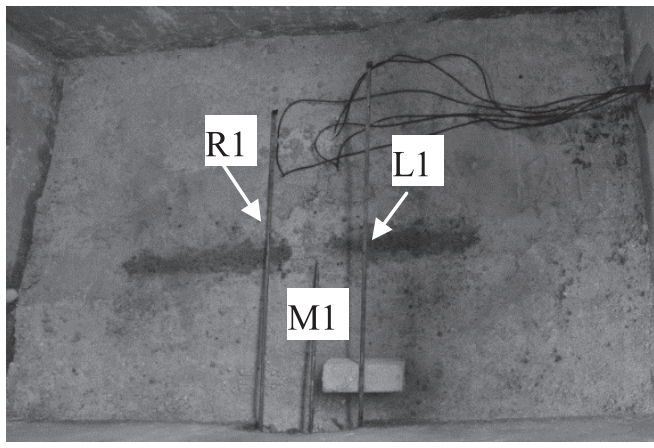

c)

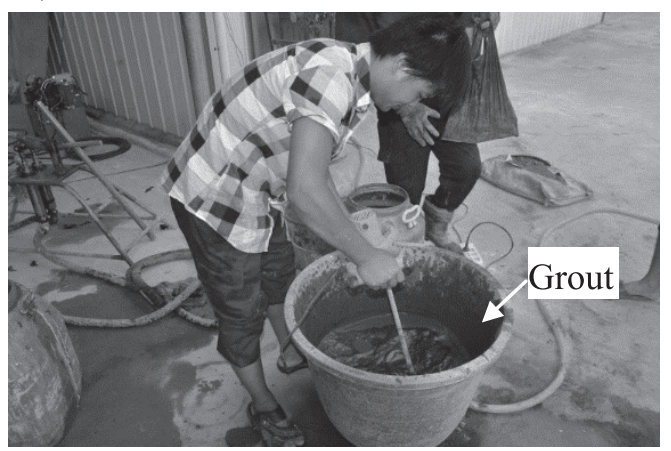

b)

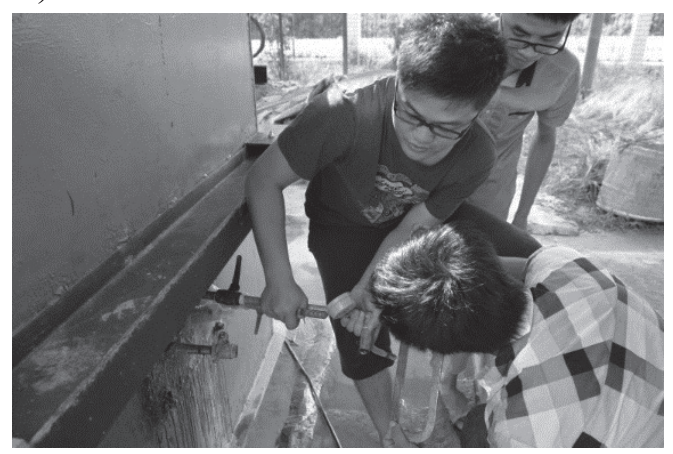

d)

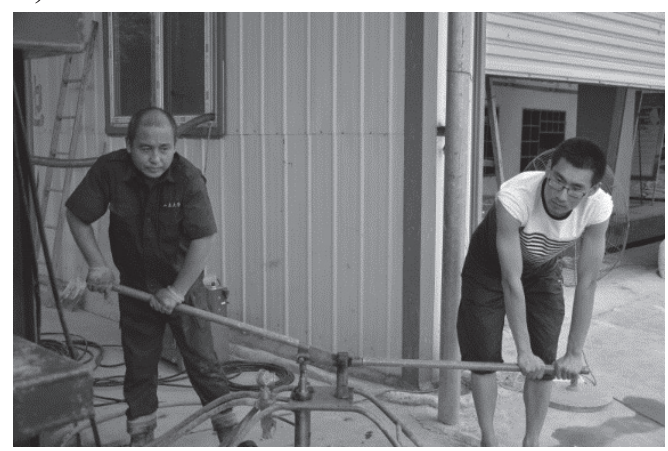

Fig. 6. Implementation of grouting: a) layout of grouting pipes, b) sealing, c) grout preparation, d) grout injection.

In order to realize grout injection under high pressure condition, the grouting pipes were connected with the setup and sealed with sealant, as shown in Fig. 6b). Fig. 6c) shows that the cement grout with a ratio of 1 was used as grouting material. After that, three grout injections were conducted by use of a manual piston grouting pump, with the maximum injection pressure and injection rate selected as $1 \mathrm{MPa}$, and $2 \sim 10 \mathrm{~L} / \mathrm{min}$, respectively. In order to prevent the damage to tunnel caused by the excessive injection pressure, the end standard of grouting is to stop grouting immediately after reaching the maximum grouting pressure.

\section{Results and Discussion}

\section{Monitored Pressure Changes by the M1 Grouting}

Fig. 7 shows that the sensors have initial pressures ranging from $20 \mathrm{kPa}$ to $50 \mathrm{kPa}$, due to the influence of the gravity of rock mass and the disturbance of water and mud inrush. Then the pressures in the rock mass increase rapidly immediately after the start of grouting. Finally, the pressures drop to stable values when the grouting was finished. Therefore, the changes in pressure can be classified into three stages: (a) initial pressure, (b) pressure induced by grouting and (c) stable pressure.

This analysis mainly focuses on the pressure induced by grouting. In order to quantify the pressure changes caused by grouting, the average pressure increment and peak pressure increment of each sensor were calculated, and they could reach $13 \mathrm{kPa} \sim 79 \mathrm{kPa}$ and $25 \mathrm{kPa} \sim 89 \mathrm{kPa}$, respectively, which could be explained by the volumetric shrinkage of the rock mass caused by the injected grout. In addition, the pressures at the spandrel and hance are relatively large, and this mainly because these two locations are prone to pressure concentration with the influence of tunnel excavation and mud inrush.

It also could be seen from Fig. 7 that some sensors show different trends, e.g. the sensor RS1SP has significantly higher pressure than others, and the pressure curves of the sensors LM1SP and RS2SP are fluctuating. This is mainly because the direction of grout flow is constantly changing, i.e. grout flow always tends to weak points in the rock mass, while weak points are also constantly changing positions due to grout injection. Therefore, the pressure at the places where the grout flows will be large. Moreover, changes in the locations of grout flow may cause pressure fluctuations.

\section{Discussion on Applied Pressure in Grouting Calculations}

In engineering applications, the pressure that drives the grout diffusion is one of the most important parameters applied in related calculations such as grout diffusion radius [13, 23], and the existing analytical models commonly used the external pipeline pressure directly, which can be monitored by the pressure gauge. However, whether the external pipeline pressure 
is the same as the actual pressure that drives the grout diffusion is controversial. Therefore, this study also aims to obtain the relationship between the external pipeline pressure and the pressure that actually drives grout diffusion, and they were monitored by the pressure gauge and FBG sensors in this test, as shown in Fig. 8.
In the M1 grouting test, it could be measured by pressure gauge that the external pipeline pressure was $100.67 \mathrm{kPa}$, as shown in Fig. 7. By calculating the difference between the peak pressure and the initial pressure, the peak pressure increment induced by grouting ranging from $17.2 \mathrm{kPa}$ to $46.5 \mathrm{kPa}$ could be obtained, as tabulated in Table 3 . It can be concluded

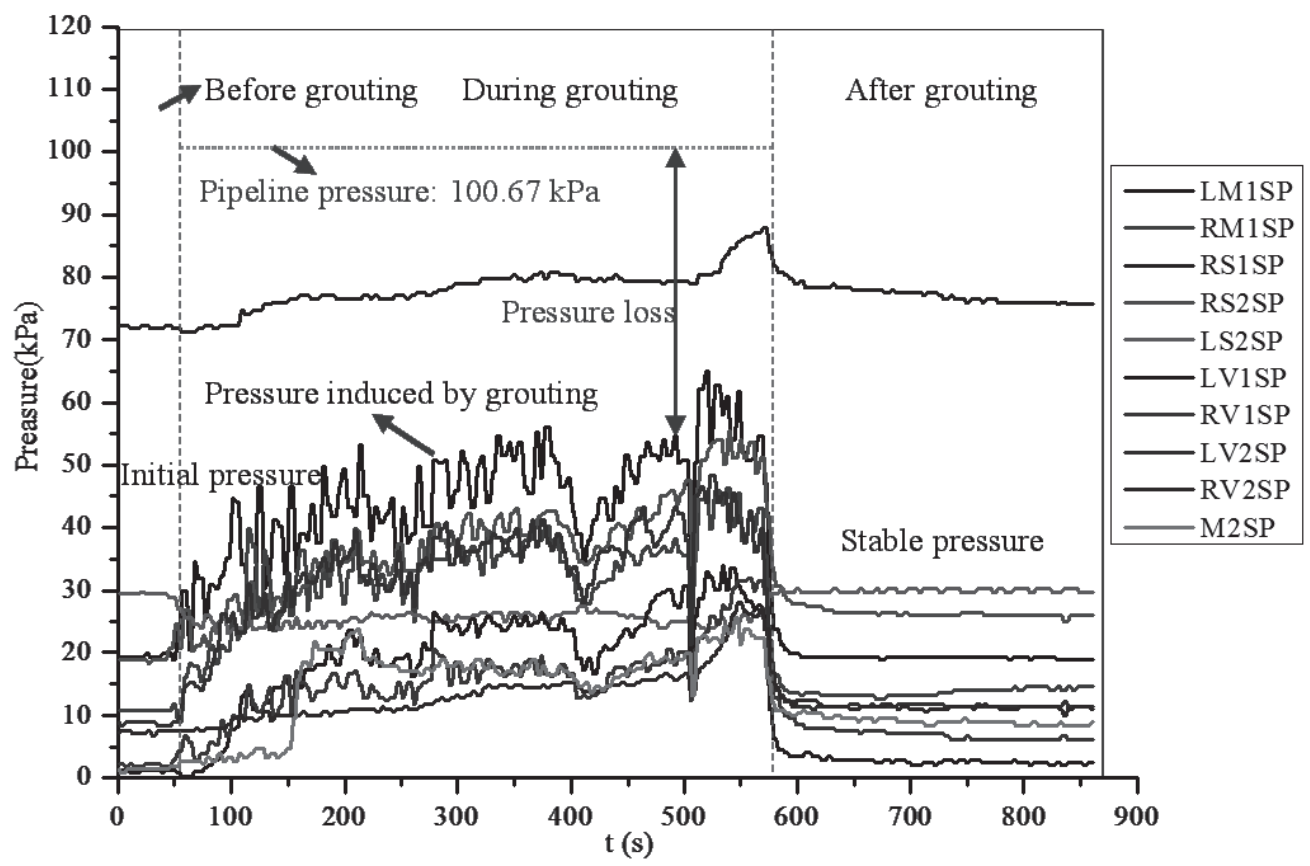

Fig. 7. The pressure curves in the M1 grouting.

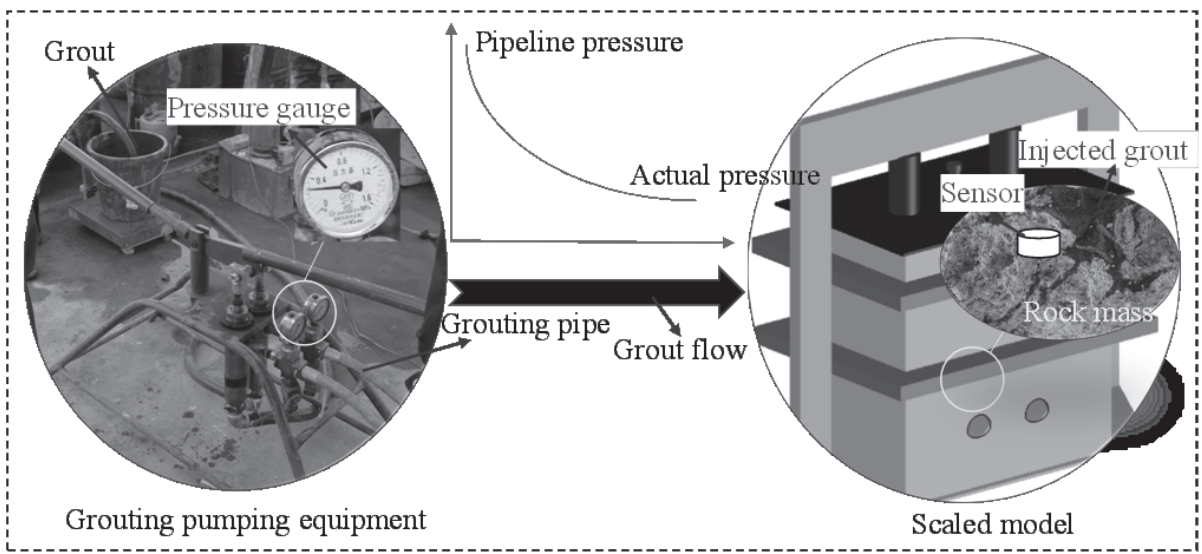

Fig. 8. The pressure curves in the M1 grouting.

Table 3. Pipeline pressure loss in the M1 grouting.

\begin{tabular}{|c|c|c|c|c|c|c|c|c|c|}
\hline Label of sensors & RS1 & RS2 & LM1 & RM1 & RV2 & LV2 & LV1 & RV1 & M2 \\
\hline Initial pressure $(\mathrm{kPa})$ & 71.8 & 19.3 & 18.5 & 11.3 & 8.1 & 7.6 & 1.9 & 2.2 & 1.9 \\
\hline Peak pressure $(\mathrm{kPa})$ & 89 & 54 & 65 & 44 & 27 & 46 & 32 & 30 & 25 \\
\hline Peak pressure increment $(\mathrm{kPa})$ & 17.2 & 34.7 & 46.5 & 32.7 & 18.9 & 38.4 & 30.1 & 27.8 & 23.1 \\
\hline Pipeline pressure loss $(\%)$ & 82.9 & 65.5 & 53.8 & 67.5 & 81.2 & 61.8 & 70.1 & 72.3 & 77.1 \\
\hline
\end{tabular}


that the pipeline pressure is significantly larger than the actual pressure that drives grout diffusion, and the pressure loss can reach $53.8 \% \sim 82.9 \%$. This is mainly because the grout first flows through pipes to the rock mass before it could diffuse, and the grout flow need to overcome the friction of the pipe wall and the viscous resistance of the grout itself. Therefore, the actual pressure that drives grout diffusion is less than the pipeline pressure.

Therefore, a certain reduction coefficient should be taken when using external pipeline pressure to calculate the grout diffusion radius in engineering applications, otherwise the calculated values will be too large.

\section{Conclusions}

In this paper, a novel method for monitoring the pressure generated by grout injection using FBG sensors is presented. A total of 14 FBG sensors were installed into the scaled model to measure the real-time pressure curves during grouting. Although this is an experimental case study, it shows the potential of sensors for pressure monitoring in practical grouting engineering. The conclusions could be drawn as follows.

(1) Due to the volumetric shrinkage of the rock mass caused by grout injection, the average pressure increment and peak pressure increment of each sensor in the M1 grouting could reach $13 \mathrm{kPa} 79 \mathrm{kPa}$ and $25 \mathrm{kPa} \sim 89 \mathrm{kPa}$, respectively.

(2) The pressures at the spandrel and hance were relatively large, and this mainly because that these two locations are prone to pressure concentration with the influence of tunnel excavation and mud inrush.

(3) The relationship between the external pipeline pressure and the pressure that actually drives grout diffusion was obtained. The pipeline pressure loss in two grout injections ranged from $53.8 \%$ to $82.9 \%$, i.e. the pipeline pressure is larger than the actual pressure that drives grout diffusion. Therefore, it is necessary that a certain reduction coefficient should be taken when using external pipeline pressure to calculate the grout diffusion radius in engineering applications.

\section{Acknowledgments}

This project was gratefully supported by the National Natural Science Foundation of China (Grant No. 51909250), Shandong Natural Science Foundation (Grant No. ZR201807080053), and Science and technology project of Housing Urban and rural construction in Shandong Province (Grant No. 2020K4-2). Great appreciation is also extended to the editorial board and the reviewers of this paper.

\section{Conflict of Interest}

The authors declare no conflict of interest.

\section{References}

1. LI M.T., ZHANG X., KUANG W., ZHOU Z. Grouting reinforcement of shallow and small clearance tunnel. Polish Journal of Environmental Studies, 30 (1), 752, 2021.

2. LIU J.G., ZHANG X., LI M.T., LAN X.D., HAO P.S. Research on permeation grouting mechanism considering gravity in the treatment of mud inrush disaster. Polish Journal of Environmental Studies, 30 (3), 2609, 2021.

3. SULUGURU A.K., JAYATHEJA M., KAR A., GUHARAY A., SURANA A.R., JAMES N. Experimental studies on the microstructural, physical and chemical characteristics of building derived materials to assess their suitability in ground improvement. Construction \& Building Materials, 156, 921, 2017.

4. LI L.P., SHANG C.S., CHU K.W. Large-scale geomechanical model tests for stability assessment of superlarge cross-section tunnel. Tunnelling and Underground Space Technology, 109, 103756, 2021.

5. HEIDARI M., TONON F. Ground reaction curve for tunnels with jet grouting umbrellas considering jet grouting hardening. International Journal of Rock Mechanics \& Mining Sciences, 76, 200, 2015.

6. LI P., ZHANG Q.S., LI S.C., ZHANG X. Time-dependent empirical model for fracture propagation in soil grouting. Tunnelling and Underground Space Technology, 94, 103, 2019.

7. ZHANG Q.S., LI P., WANG G. Parameters optimization of curtain grouting reinforcement cycle in Yonglian tunnel and its application. Mathematical Problems in Engineering, 12, 2, 2015.

8. ZHANG Q.S., LI P., ZHANG X. Model test of grouting strengthening mechanism for fault gouge of tunnel. Chinese Journal of Rock Mechanics \& Engineering, 34 (5), 924, 2015.

9. DU X.M., FANG H.Y., WANG S.Y., XUE B.H., WANG F.M. Experimental and practical investigation of the sealing efficiency of cement grouting in tortuous fractures with flowing water. Tunnelling and Underground Space Technology, 108, 103693, 2021.

10. BOLISETTI T., REITSMA S., BALACHANDAR R. Experimental investigations of colloidal silica grouting in porous media. Journal of geotechnical and geoenvironmental engineering, 135 (5), 697, 2009.

11. GOTHÄLL R., STILLE B. Fracture-fracture interaction during grouting. Tunnelling and Underground Space Technology, 25 (3), 199, 2010.

12. YUN J.W., PARK J.J., KWON Y.S. Cement-Based Fracture Grouting Phenomenon of Weathered Granite Soil. KSCE Journal of Civil Engineering, 21 (1), 1, 2016.

13. MURDOCH L.C. Hydraulic fracturing of soil during laboratory experiments. Part 1. Methods and observations. Geotechnique, 43, 255, 1993.

14. MURDOCH L.C. Hydraulic fracturing of soil during laboratory experiments Part 2. Propagation. Geotechnique, 43, 267, 1993.

15. MURDOCH L.C. Hydraulic fracturing of soil during laboratory experiments, Part 3. Theoretical analysis. Geotechnique, 43, 27, 1993. 
16. LI S.C., ZHANG X., ZHANG Q.S. Research on mechanism of grout diffusion of dynamic grouting and plugging method in water inrush of underground engineering. Chinese Journal of Rock Mechanics \& Engineering, 30, 2377, 2011.

17. SUI W., LIU J., HU W. Experimental investigation on sealing efficiency of chemical grouting in rock fracture with flowing water. Tunnelling and Underground Space Technology, 50, 239, 2015.

18. LI P., ZHANG Q.S. Grouting Diffusion Characteristics in Faults Considering the Interaction of Multiple Grouting. International Journal of Geomechanics, 17 (5), $1,2016$.

19. LI P., ZHANG Q.S., ZHANG X. Analysis of fracture grouting mechanism based on model test. Rock and Soil Mechanics, 35 (11), 3221, 2014.

20. LI P., XIONG J.C., LIU Y. A self-control and visual grouting model test system and measurement method. Measurement, 154, 107481, 2020.
21. LI P., WANG C.Q., FAN G.X., LIU Y., XIONG J.C. Study on time-varying viscosity of cement and sodium silicate grout under seawater condition. Construction and Building Materials, 269, 121223, 2021.

22. FATTAH M.Y., AL-ANI M.M., AL-LAMY M.T.A Studying collapse potential of gypseous soil treated by grouting. Soils \& Foundations, 54 (3), 396, 2014.

23. BEZUIJEN A., TE GROTENHUIS R., VAN TOL A.F., BOSCH J.W., HAASNOOT J.K. Analytical model for fracture grouting in sand. Journal of Geotechnical and Geoenvironmental Engineering, 137 (6), 611, 2010.

24. SALIMIAN M.H., BAGHBANAN A., HASHEMOLHOSSEINI H. Effect of grouting on shear behavior of rock joint. International Journal of Rock Mechanics \& Mining Sciences, 98, 159, 2017.

25. CHUN B.S., YONG J.L., CHUNG H.I. Effectiveness of leakage control after application of permeation grouting to earth fill dam. KSCE Journal of Civil Engineering, 10 (6), 405, 2006. 